\title{
Long-Lasting Impact of Early Life Immune Stress on Neuroimmune Functions
}

\author{
Abdeslam Mouihate \\ Department of Physiology, Faculty of Medicine, Kuwait University, Safat, Kuwait
}

\section{Key Words}

Hypothalamus-pituitary-adrenal axis · Toll-like receptors .

Cyclooxygenase type $2 \cdot$ Inflammatory cytokines .

Antipyretic

\begin{abstract}
Fever is one major cardinal sign of disease. It results from an intricate interplay between the immune system and the central nervous system. Bacterial or viral infections activate peripheral immune competent organs which send inflammatory signals to the brain and lead to an increase in body temperature. The increased body temperature creates a conducive environment to optimize the body's fight against the infection. A large body of experimental evidence suggests that early life bacterial or viral infections can lead to a long-lasting impact on this natural febrile response. The early life pathogenic encounter heightens the hypothalamic-pituitary-adrenal axis response, dampens the innate immune system, and consequently reduces the febrile response to a subsequent immune challenge during adulthood. This 'programming' effect operates only when such early life immune challenges occur during a critical window of either prenatal or postnatal development. In this review, the mechanisms underlying the long-lasting impact of perinatal immune challenge on adult fever are addressed.
\end{abstract}

(c) 2013 S. Karger AG, Basel

\begin{tabular}{ll}
\hline KARGER & $\begin{array}{l}\text { ( } 2013 \text { S. Karger AG, Basel } \\
1011-7571 / 13 / 0227-0003 \$ 38.00 / 0\end{array}$ \\
$\begin{array}{l}\text { E-Mail karger@karger.com } \\
\text { www.karger.com/mpp }\end{array}$ & $\begin{array}{l}\text { This is an Open Access article licensed under the terms of the } \\
\text { Creative Commons Attribution-NonCommercial } 3.0 \text { Un- } \\
\text { ported license (CC BY-NC) (www.karger.com/OA-license), } \\
\text { applicable to the online version of the article only. Distribu- } \\
\text { tion permitted for non-commercial purposes only. }\end{array}$
\end{tabular}

\section{Fever Results from a Cross Talk between the Immune and the Nervous System}

Fever is often confused with hyperthermia. While hyperthermia refers to a passive increase in body temperature, fever is the result of a regulated increase in the thermoregulatory set point [1]. Several studies strongly suggest that the thermoregulatory center is located in the preoptic region of the hypothalamus $[2,3]$. The most commonly used model of experimental fever involves a systemic injection of lipopolysaccharide (LPS), an active ingredient of the outer membrane of Gram-negative bacteria which activates immune competent cells [4]. Upon LPS binding to its receptor complex composed of toll-like receptor 4 (TLR4) and CD14 [5-7], a cascade of intracellular signaling pathways is activated, culminating in the translocation of the nuclear factor $\kappa \mathrm{B}(\mathrm{NF} \kappa \mathrm{B})$ from the cytoplasm into the nucleus $[8,9]$. NFkB binds to the promoter regions of several proinflammatory genes including interleukin (IL)- $1 \beta$, IL- 6 , and tumor necrosis factor- $\alpha$ (TNF- $\alpha$ ) and induces their expression [10]. A large body of evidence suggests that the proinflammatory cytokines or their secondary signals access the fever-controlling region of the hypothalamus via either hormonal or neuronal pathways [11-13]. This immune-to-brain signaling leads to the induction of cyclooxygenase type 2 (COX-2) 
within the preoptic area of the hypothalamus $[14,15]$. COX-2 is the rate-limiting enzyme for the synthesis of prostaglandin of the $\mathrm{E}_{2}$ series $\left(\mathrm{PGE}_{2}\right)$. Once produced, $\mathrm{PGE}_{2}$ binds to its E-prostanoid receptor type 3 (EP3) located in the preoptic area of the hypothalamus [16-18]. $\mathrm{PGE}_{2}$-EP3 interaction leads to a reduced GABAergic inhibitory tone and an enhanced glutamatergic stimulatory effect on heat production from brown adipose tissue [19].

While the proinflammatory cytokines are involved in the initiation of fever, they also activate an antipyretic pathway via a concerted action on the hypothalamic-pituitary-adrenal (HPA) axis [10, 20, 21]. Cortisol (corticosterone in rodents), the end product of HPA axis activity, is known to dampen inflammation and its resulting febrile response [22-24], likely via an inhibitory action on the NFKB signaling pathway [25]. In addition to the antipyretic effect of cortisol, anti-inflammatory cytokines such as IL-4 and IL-10 [26-29] and neuropeptides such as vasopressin are also known as endogenous antipyretics [30-32].

\section{Neonatal Immune Challenge Alters Adult Fever}

Fever is regarded as a malaise that needs to be 'treated'. However, it is now accepted that fever is an adaptive response to pathogens. It creates a conducive environment to help the immune system fight off the infection $[1,33]$. Thus, any alteration in the ability to mount an appropriate febrile response could have a negative health impact. A large body of evidence strongly suggests that early life experience with pathogens could 'reprogram' the febrile response to pathogens encountered during adulthood.

The indication that early life immune challenge could alter the febrile response in adults stemmed from a series of studies showing that injection of a mild dose of LPS into neonatal rodents leads to an enhanced HPA axis activity during adult life [34-36]. Because corticosterone, the end product of HPA axis activity, dampens fever, it was hypothesized that a neonatal immune challenge could alter the adult fever response. Indeed, LPS administration to rats during the neonatal period led to a dampened febrile response to LPS when these animals reached adulthood [37-42]. The programming effect of an early life immune challenge on fever seems to be dependent on the developmental stage at which the immune system was initially mobilized. LPS injection on either postnatal day (PND) 7 or PND28 did not alter adult LPS fever, but administration of LPS on PND14 or PND21 attenuated adult LPS fever [43]. Interestingly these attenuated febrile responses were associated with blunted LPS-induced COX-2 expression in the fever-controlling regions of the hypothalamus $[40,43]$.

These long-lasting effects were also accompanied by an enhanced, albeit transient, adult HPA axis responsiveness to LPS. This enhanced HPA axis responsiveness was lost when adult animals were subjected to adrenalectomy combined with a constant supply of physiological doses of corticosterone or when adult rats were given RU486, a glucocorticoid receptor antagonist [39]. Similarly, the heightened HPA activity led to attenuated levels of circulating proinflammatory cytokines (IL- $\beta$, IL- 6 , and TNFa) [39] and to reduced levels of their gene expression in the hypothalamus [44], likely through a reduced activity of the NFKB signaling pathway [39]. These attenuated cytokine responses were also abolished by either adrenalectomy or blockade of glucocorticoid receptors [39]. Thus, it seems that the long-lasting impact of an early life immune challenge on the adult febrile response is strongly linked to the heightened HPA responsiveness.

\section{Homotypic versus Heterotypic Stimulations}

The programming effect of neonatal immune challenge is not limited to bacterial LPS. In fact, early life exposure to the viral mimetic polyinosinic:polycytidylic acid (Poly I:C), a TLR3 activator, also dampened adult Poly I:C-induced fever and resulted in an upregulated HPA axis response to TLR3 activation during adulthood [37]. It is now clear that the HPA axis is at the center of the programming effects of TLR3 and TLR4 activations. Thus, one could assume that neonatal immune activation of TLR4 (with LPS) leads to a heightened HPA axis responsiveness and would consequently dampen the adult fever response to TLR 3 activation and vice versa. This was not the case. Early life exposure to Poly I:C did not affect adult LPS-induced fever. Inversely, neonatal exposure to bacterial LPS did not affect Poly I:C-induced fever in adults [37]. The requirement of this homotypic stimulation is further supported by the lack of an LPS programming effect on adult IL-1 $\beta$-induced fever [40]. In order to sustain this long-lasting programming effect on fever, it seems necessary that the same receptor (e.g. TLR3 or TLR4) should be activated at both neonatal and adult ages. Thus, these homotypic stimulations (LPS-LPS or Poly I:C-Poly I:C) effects may operate through a specific action on their own signaling pathways $[6,9,45]$. Finally, it is interesting to note that early life injection of a nonlethal dose of live Escherichia coli does not impact adult 
LPS fever, but rather it leads to a prolonged adult fever induced by E. coli [46]. This apparent discrepancy is probably related to distinct acute inflammatory responses triggered by LPS and live E. coli [47]. This distinct acute inflammatory response could be brought about by the additional action of the different active components of $E$. coli (in addition to LPS) on different TLRs leading to different intracellular signaling pathways and gene expression.

\section{Prenatal Immune Challenge and the Innate Immune Response}

Prenatal immune challenge also results in altered HPA axis activity in adult offspring [48], which could impact the adult febrile response. Few studies have addressed this question. LPS injection in sheep during the last period of pregnancy (during the last month of gestation) increased corticosterone levels and dampened their eyes' temperature response to a subsequent LPS injection at a juvenile age [49]. Similarly, adult offspring of pregnant guinea pigs given repeated LPS injections in the last phase of pregnancy showed a reduced LPS-induced fever $3 \mathrm{~h}$ after LPS administration [50]. Surprisingly, data on the longlasting effects of prenatal immune challenge in rats were missing. We recently explored the possibility that prenatal immune challenge impacts the adult rat febrile response. LPS administration to dams on gestational day (GD) 15 resulted in a significant reduction in LPS fever in adult offspring. Such an effect was absent if the dams were given LPS on either GD12 or GD19. Interestingly, the adult corticosterone response to LPS was transiently but significantly enhanced while COX-2 induction in the fever-controlling region of the hypothalamus was reduced specifically in offspring born to dams given LPS on GD15 [51].

It is unclear whether this enhanced corticosterone response would lead to a dampened production of inflammatory cytokines. However, serum levels of IL-1 $\beta$, IL-6, and TNF- $\alpha$ induced by LPS as well as LPS-induced mRNA of inflammatory cytokines in the brains of 3-week-old rats were reduced in those born to dams given LPS on GD18 [52]. Repeated prenatal LPS injections (on GD16, GD18, and GD20) also resulted in reduced LPS-induced TNF- $\alpha$, but no significant change in LPS-induced IL- $1 \beta$ was observed [53]. Thus, the dampened innate immune response in adult offspring born to immune challenged dams during pregnancy could underlie the reduced febrile response.

Perinatal Immune Stress Programs the Adult Febrile Response

\section{More than Just Fever Programming}

A substantial amount of knowledge has been accumulated on the long-lasting impact of perinatal immune challenge on many physiological parameters. Aside from the HPA axis alteration, perinatal immune challenge has broader effects on brain development and plasticity. Experimentally, early life immune stimulation has been shown to impact several pathophysiological parameters such as alteration of pain perception [54], impairments in learning and memory [55-57], brain cell death secondary to ischemia [58], loss of dopaminergic neurons in the nigrostriatal brain area (a phenomenon strongly associated with Parkinson's disease) [59,60], susceptibility to seizures [61], exacerbation of experimental colitis [62], and suppression of experimental autoimmune encephalomyelitis, an experimental model of multiple sclerosis [63]. Despite this large amount of experimental evidence on the long-lasting and profound impact of early life immune challenge, we still do not know how these 'imprinting' processes are triggered, nor do we have a good understanding of how they last throughout life. More research is needed to explore the mechanisms through which an early life immune challenge leaves a permanent pathophysiological 'trace' in developing brains. One such promising research avenue is the lasting nongenomic modification termed epigenetic [64-66]. Indeed, early life challenges such as stress and poor nutrition or levels of maternal care could 'permanently' turn on or off some genes via acetylation or methylation of their promoter regions [6772]. It is conceivable that a permanent alteration in the expression of such genes could form the basis for a sustained change in the set point of different physiological parameters and could explain the lasting impact of early life experiences on brain function and plasticity $[65,73$, 74]. Interestingly, some of these epigenetic modifications could be 'passed on' to offspring, thus allowing these genetic modifications to potentially last into future generations for, perhaps, their adaptive values $[75,76]$. Whether an early life immune challenge exerts its long-lasting effects via epigenetic modifications is still an open question.

\section{Conclusion}

Fever is an adaptive response to infection. Any alteration of the febrile response can lead to deleterious effects. While exposure to pathogens invariably leads to alteration of the thermoregulatory set point, the magnitude of the fever response can be permanently programmed by

Med Princ Pract 2013;22(suppl 1):3-7 
early life exposure to viral and bacterial pathogens. This programming effect occurs during both pre- and postnatal periods when the brain areas involved in thermoregulation are emerging and/or maturing. It has been repeatedly observed that early life exposure to pathogens permanently heightens HPA axis activity. Aside from its impact on the febrile response, this enhanced HPA axis contributes to a myriad of pathophysiological conditions. Future studies should explore whether the programming effects of early life immune challenge are sustained by epigenetic modifications of genes required for the thermoregulatory response (e.g. cox-2) or are due to permanent plastic changes in the brain areas/structures involved in the neuroimmune responses.

\section{Acknowledgment}

Parts of this work were performed in the laboratory of Dr. Abdeslam Mouihate and were supported by Kuwait University research grant No. MY01/09. The author wishes to thank Dr. Samuel B. Kombian for reading the manuscript.

\section{Disclosure Statement}

The author declares that no financial or other conflict of interest exists in relation to the content of the article.

\section{References}

1 Kluger MJ: Fever: role of pyrogens and cryogens. Physiol Rev 1991;71:93-127.

2 Lipton JM, Welch JP, Clark WG: Changes in body temperature produced by injecting prostaglandin E1, EGTA and bacterial endotoxins into the $\mathrm{PO}-\mathrm{AH}$ region and the medulla oblongata of the rat. Experientia 1973;29: 806-808.

3 Scammell TE, Elmquist JK, Griffin JD, et al: Ventromedial preoptic prostaglandin E2 activates fever-producing autonomic pathways. J Neurosci 1996; 16:6246-6254.

-4 Romanovsky AA, Almeida MC, Aronoff DM, et al: Fever and hypothermia in systemic inflammation: recent discoveries and revisions. Front Biosci 2005;10:2193-2216.

5 Takeda K, Akira S: Toll-like receptors in innate immunity. Int Immunol 2005;17:1-14.

-6 Takeda K, Kaisho T, Akira S: Toll-like receptors. Annu Rev Immunol 2003;21:335-376.

7 Laflamme N, Rivest S: Toll-like receptor 4: the missing link of the cerebral innate immune response triggered by circulating gram-negative bacterial cell wall components. FASEB J 2001;15:155-163.

8 Hayden MS, Ghosh S: Signaling to NF-kappaB. Genes Dev 2004;18:2195-2224.

9 Kawai T, Akira S: The role of pattern-recognition receptors in innate immunity: update on Toll-like receptors. Nat Immunol 2010;11: 373-384.

10 Rivest S: How circulating cytokines trigger the neural circuits that control the hypothalamicpituitary-adrenal axis. Psychoneuroendocrinology 2001;26:761-788.

11 Blatteis CM: The onset of fever: new insights into its mechanism. Prog Brain Res 2007;162: 3-14.

12 Blatteis CM: Endotoxic fever: new concepts of its regulation suggest new approaches to its management. Pharmacol Ther 2006;111:194223.
13 Blatteis CM, Sehic E, Li S: Afferent pathways of pyrogen signaling. Ann NY Acad Sci 1998; 856:95-107.

14 Cao C, Matsumura K, Yamagata K, et al: Involvement of cyclooxygenase-2 in LPS-induced fever and regulation of its mRNA by LPS in the rat brain. Am J Physiol 1997; 272:R1712-R1725.

15 Steiner AA, Ivanov AI, Serrats J, et al: Cellular and molecular bases of the initiation of fever. PLoS Biol 2006;4:1517-1524.

16 Nakamura Y, Nakamura K, Morrison SF: Different populations of prostaglandin EP3 receptor-expressing preoptic neurons project to two fever-mediating sympathoexcitatory brain regions. Neuroscience 2009;161:614620.

17 Lazarus M, Yoshida K, Coppari R, et al: EP3 prostaglandin receptors in the median preoptic nucleus are critical for fever responses. Nat Neurosci 2007; 10:1131-1133.

18 Nakamura Y, Nakamura K, Matsumura K, et al: Direct pyrogenic input from prostaglandin EP3 receptor-expressing preoptic neurons to the dorsomedial hypothalamus. Eur J Neurosci 2005;22:3137-3146.

19 Morrison SF, Madden CJ, Tupone D: Central control of brown adipose tissue thermogenesis. Front Endocrinol (Lausanne) DOI: 10.3389/fendo.2012.00005

20 Mouihate A, Galic MA, Ellis SL, et al: Early life activation of toll-like receptor 4 reprograms neural anti-inflammatory pathways. J Neurosci 2010;30:7975-7983.

21 Rivest S: Interactions between the immune and neuroendocrine systems. Prog Brain Res 2010;181:43-53.

22 Morrow LE, McClellan JL, Conn CA, et al: Glucocorticoids alter fever and IL-6 responses to psychological stress and to lipopolysaccharide. Am J Physiol 1993;264:R1010R1016.
23 Kozak W, Kluger MJ, Tesfaigzi J, et al: Molecular mechanisms of fever and endogenous antipyresis. Ann NY Acad Sci 2000;917:121-134:

24 Morrow LE, McClellan JL, Klir JJ, et al: The CNS site of glucocorticoid negative feedback during LPS- and psychological stress-induced fevers. Am J Physiol 1996;271:R732-R737.

25 De BK, Haegeman G: Minireview: latest perspectives on antiinflammatory actions of glucocorticoids. Mol Endocrinol 2009;23:281291.

26 Cartmell T, Ball C, Bristow AF, et al: Endogenous interleukin-10 is required for the defervescence of fever evoked by local lipopolysaccharide-induced and Staphylococcus aureusinduced inflammation in rats. J Physiol 2003; 549:653-664.

27 Ledeboer A, Binnekade R, Breve JJ, et al: Sitespecific modulation of LPS-induced fever and interleukin- 1 beta expression in rats by interleukin-10. Am J Physiol Regul Integr Comp Physiol 2002;282:R1762-R1772.

28 Kao CH, Huang WT, Lin MT, et al: Central interleukin-10 attenuated lipopolysaccharide-induced changes in core temperature and hypothalamic glutamate, hydroxyl radicals and prostaglandin-E(2). Eur J Pharmacol 2011;654:187-193.

29 Ledeboer A, Breve JJ, Poole S, et al: Interleukin-10, interleukin-4, and transforming growth factor-beta differentially regulate lipopolysaccharide-induced production of pro-inflammatory cytokines and nitric oxide in co-cultures of rat astroglial and microglial cells. Glia 2000;30:134-142.

30 Pittman QJ, Chen X, Mouihate A, et al: Arginine vasopressin, fever and temperature regulation. Prog Brain Res 1998;119:383-392.

31 Pittman QJ, Chen X, Mouihate A, et al: Vasopressin-induced antipyresis: sex- and experience-dependent febrile responses. Ann NY Acad Sci 1998;856:53-61. 
-32 Pittman QJ: A neuro-endocrine-immune symphony. J Neuroendocrinol 2011;23:12961297.

33 Kluger MJ, Kozak W, Conn CA, et al: Role of fever in disease. Ann NY Acad Sci 1998;856: 224-233.

34 Shanks N, Windle RJ, Perks PA, et al: Earlylife exposure to endotoxin alters hypothalamic-pituitary-adrenal function and predisposition to inflammation. Proc Natl Acad Sci USA 2000;97:5645-5650.

- 35 Shanks N, Larocque S, Meaney MJ: Neonatal endotoxin exposure alters the development of the hypothalamic-pituitary-adrenal axis: early illness and later responsivity to stress. J Neurosci 1995; 15:376-384.

- 36 Hodgson DM, Knott B, Walker FR: Neonatal endotoxin exposure influences HPA responsivity and impairs tumor immunity in Fischer 344 rats in adulthood. Pediatr Res 2001;50: 750-755.

37 Ellis S, Mouihate A, Pittman QJ: Neonatal programming of the rat neuroimmune response: stimulus specific changes elicited by bacterial and viral mimetics. J Physiol 2006; 15:695-701.

- 38 Spencer SJ, Boisse L, Mouihate A, et al: Long term alterations in neuroimmune responses of female rats after neonatal exposure to lipopolysaccharide. Brain Behav Immun 2006;20: 325-330.

-39 Ellis S, Mouihate A, Pittman QJ: Early life immune challenge alters innate immune responses to lipopolysaccharide: implications for host defense as adults. FASEB J 2005; 19 : 1519-1521.

40 Boisse L, Mouihate A, Ellis S, et al: Long-term alterations in neuroimmune responses after neonatal exposure to lipopolysaccharide. J Neurosci 2004;24:4928-4934.

-41 Walker FR, Hodyl NA, Krivanek KM, et al: Early life host-bacteria relations and development: long-term individual differences in neuroimmune function following neonatal endotoxin challenge. Physiol Behav 2006;87: 126-134.

42 Saia RS, Bertozi G, Cunha FQ, et al: Estradiol and thermoregulation in adult endotoxemic rats exposed to lipopolysaccharide in neonatal life. Acta Physiol (Oxf) 2011;203:429-439.

-43 Spencer SJ, Martin S, Mouihate A, et al: Earlylife immune challenge: defining a critical window for effects on adult responses to immune challenge. Neuropsychopharmacology 2006; 31:1910-1918.

-44 Iwasa T, Matsuzaki T, Murakami M, et al: Neonatal lipopolysaccharide exposure attenuates the homotypic stress-induced suppression of $\mathrm{LH}$ secretion in adulthood in male rat. Int J Dev Neurosci 2009;27:345-349.

-45 Casanova JL, Abel L, Quintana-Murci L: Human TLRs and IL-1Rs in host defense: natural insights from evolutionary, epidemiological, and clinical genetics. Annu Rev Immunol 2011;29:447-491.
46 Bilbo SD, Wieseler JL, Barrientos RM, et al: Neonatal bacterial infection alters fever to live and simulated infections in adulthood. Psychoneuroendocrinology 2010;35:369-381.

47 Schwarz JM, Bilbo SD: LPS elicits a much larger and broader inflammatory response than Escherichia coli infection within the hippocampus of neonatal rats. Neurosci Lett 2011;497:110-115.

48 Reul JM, Stec I, Wiegers GJ, et al: Prenatal immune challenge alters the hypothalamic-pituitary-adrenocortical axis in adult rats. J Clin Invest 1994;93:2600-2607.

49 Fisher RE, Karrow NA, Quinton M, et al: Endotoxin exposure during late pregnancy alters ovine offspring febrile and hypothalamic-pituitary-adrenal axis responsiveness later in life. Stress 2010;13:334-342.

50 Hodyl NA, Walker FR, Krivanek KM, et al: Modelling prenatal bacterial infection: functional consequences of altered hypothalamic pituitary adrenal axis development. Behav Brain Res 2007;178:108-114.

51 Mouihate A: Prenatal immune stress in rats dampens fever during adulthood. Dev Neurosci 2012;34:318-326.

52 Lasala N, Zhou H: Effects of maternal exposure to LPS on the inflammatory response in the offspring. J Neuroimmunol 2007;189:95101.

53 Hodyl NA, Krivanek KM, Lawrence E, et al: Prenatal exposure to a pro-inflammatory stimulus causes delays in the development of the innate immune response to LPS in the offspring. J Neuroimmunol 2007;190:61-71.

- 54 Boisse L, Spencer SJ, Mouihate A, et al: Neonatal immune challenge alters nociception in the adult rat. Pain 2005;119:133-141.

55 Bilbo SD, Biedenkapp JC, Der-Avakian A, et al: Neonatal infection-induced memory impairment after lipopolysaccharide in adulthood is prevented via caspase-1 inhibition. J Neurosci 2005;25:8000-8009.

56 Bilbo SD, Levkoff LH, Mahoney JH, et al: Neonatal infection induces memory impairments following an immune challenge in adulthood. Behav Neurosci 2005;119:293301.

57 Harre EM, Galic MA, Mouihate A, et al: Neonatal inflammation produces selective behavioural deficits and alters N-methyl-D-aspartate receptor subunit mRNA in the adult rat brain. Eur J Neurosci 2008;27:644-653.

58 Spencer SJ, Auer RN, Pittman QJ: Rat neonatal immune challenge alters adult responses to cerebral ischaemia. J Cereb Blood Flow Metab 2006;26:456-467.

59 Fan LW, Tien LT, Lin RC, et al: Neonatal exposure to lipopolysaccharide enhances vulnerability of nigrostriatal dopaminergic neurons to rotenone neurotoxicity in later life. Neurobiol Dis 2011;44:304-316.

60 Fan LW, Tien LT, Zheng B, et al: Dopaminergic neuronal injury in the adult rat brain following neonatal exposure to lipopolysaccharide and the silent neurotoxicity. Brain Behav Immun 2011;25:286-297.
61 Galic MA, Riazi K, Heida JG, et al: Postnatal inflammation increases seizure susceptibility in adult rats. J Neurosci 2008;28:6904-6913.

62 Spencer SJ, Hyland NP, Sharkey KA, et al: Neonatal immune challenge exacerbates experimental colitis in adult rats: potential role for TNF-alpha. Am J Physiol Regul Integr Comp Physiol 2007;292:R308-R315.

63 Ellestad KK, Tsutsui S, Noorbakhsh F, et al: Early life exposure to lipopolysaccharide suppresses experimental autoimmune encephalomyelitis by promoting tolerogenic dendritic cells and regulatory T cells. J Immunol 2009; 183:298-309.

64 McGowan PO, Suderman M, Sasaki A, et al: Broad epigenetic signature of maternal care in the brain of adult rats. PLoS One 2011; 6:e14739.

65 Meaney MJ, Ferguson-Smith AC: Epigenetic regulation of the neural transcriptome: the meaning of the marks. Nat Neurosci 2010;13: 1313-1318.

-66 Murgatroyd C, Spengler D: Genetic variation in the epigenetic machinery and mental health. Curr Psychiatry Rep 2012;14:138-149.

67 Zhang TY, Meaney MJ: Epigenetics and the environmental regulation of the genome and its function. Annu Rev Psychol 2010;61:439466, C1-C3.

68 Hirabayashi Y, Gotoh Y: Epigenetic control of neural precursor cell fate during development. Nat Rev Neurosci 2010;11:377-388.

69 Jakovcevski M, Akbarian S: Epigenetic mechanisms in neurological disease. Nat Med 2012; 18:1194-1204.

70 Zhang TY, Labonte B, Wen XL, et al: Epigenetic mechanisms for the early environmental regulation of hippocampal glucocorticoid receptor gene expression in rodents and humans. Neuropsychopharmacology 2013;38: 111-123.

71 Gabory A, Attig L, Junien C: Developmental programming and epigenetics. Am J Clin Nutr 2011;94:1943S-1952S.

72 Murgatroyd C, Spengler D: Epigenetic programming of the HPA axis: early life decides. Stress 2011;14:581-589.

-73 Szyf M, Weaver IC, Champagne FA, et al: Maternal programming of steroid receptor expression and phenotype through DNA methylation in the rat. Front Neuroendocrinol 2005;26:139-162.

74 Kolb B, Mychasiuk R, Williams P, et al: Brain plasticity and recovery from early cortical injury. Dev Med Child Neurol 2011;53(suppl 4):4-8.

-75 Walker AK, Hawkins G, Sominsky L, et al: Transgenerational transmission of anxiety induced by neonatal exposure to lipopolysaccharide: implications for male and female germ lines. Psychoneuroendocrinology 2012; 37:1320-1335.

76 Crews D, Gillette R, Scarpino SV, et al: Epigenetic transgenerational inheritance of altered stress responses. Proc Natl Acad Sci USA 2012;109:9143-9148.
Perinatal Immune Stress Programs the Adult Febrile Response
Med Princ Pract 2013;22(suppl 1):3-7 DOI: $10.1159 / 000354199$ 